\title{
Demographic and Risk Factors of Intracerebral Hemorrhage Stroke Patients in Dr. Hasan Sadikin General Hospital Bandung in 2007-2016
}

\author{
Sabrina Putri Lofissa, ${ }^{1}$ Paulus Anam Ong, ${ }^{2}$ Nur Atik ${ }^{3}$ \\ ${ }^{1}$ Faculty of Medicine Universitas Padjadjaran, ${ }^{2}$ Department of Neurology Faculty of Medicine \\ Universitas Padjadjaran/Dr. Hasan Sadikin General Hospital Bandung, ${ }^{3}$ Department of Basic \\ Medicine Faculty of Medicine Universitas Padjadjaran Bandung, Indonesia
}

\begin{abstract}
Background: Intracerebral hemorrhage stroke is a type of stroke which is considered to have a higher mortality risk than ischemic stroke. Preventive programs are needed to minimize stroke cases by reducing the risk factors. This study aimed to identify the demographic and risk factors of intracerebral hemorrhage stroke patients in Dr. Hasan Sadikin General Hospital Bandung in 2007-2016.

Methods: This was a descriptive cross sectional study. Data were obtained from Dr. Hasan Sadikin General Hospital medical resume January 2007- December 2016 by total sampling. Subjects of this study were intracerebral hemorrhage stroke patients hospitalized in Dr. Hasan Sadikin General Hospital. The period of study was from August 2016 until May 2017. Variables included in this study were gender, occupation, education level, age; risk factors such as hypertension, dyslipidemia, diabetes mellitus, hyperuricemia, and kidney disease. The collected data were presented in percentage.

Results: The highest demographic prevalence in 10 years was in female, non-occupational person, elementary school graduate, and frequently found in the 50-59 age group. The highest risk factor was hypertension, but it slightly decreased from $78.8 \%$ in $2007-2008$ to $55.3 \%$ in $2015-2016$, followed by dyslipidemia, diabetes mellitus, hyperuricemia which increased in 2007-2008 and 2015-2016. (Dyslipidemia: from 8.1\% to 23.8\%; Hyperuricemia: from 2.5\% to11.2\%; Diabetes Mellitus: from 6.6\% to $8.9 \%$ ).

Conclusions: The demographic of intracerebral hemorrhage stroke shows a high prevalence found in females, older age, non-occupational persons, and elementary school graduates. Among the risk factors, hypertension is most likely to happen in ten years.
\end{abstract}

Keywords: Demography, intracerebral hemorrhage stroke, risk factors

\section{Introduction}

Intracerebral hemorrhage stroke is one type of stroke which is considered to have a higher mortality risk than ischemic stroke. ${ }^{1}$ According to the World Health Organization (WHO), stroke was defined as rapidly developed clinical signs of focal disturbance of cerebral function, lasting more than 24 hours or leading to death, with no other apparent cause than cerebrovascular disease. ${ }^{2}$ Based on a Basic Health Research (Riset Kesehatan Dasar, Riskesdas), the national stroke prevalence showed an increased prevalence from 8.3 per 1000 population in 2007 to 12.1 per 1000 population in $2013 .{ }^{3}$ According to WHO, the stroke itself ranks first in the mortality rate in
Indonesia about 328.000 in $2012 .{ }^{4}$ West Java Province has the highest estimated number of stroke patients around 238.001 people $(7.4 \%$ ) and 533.895 people $(16.6 \%)$ based on health personnel (Tenaga kesehatan, Nakes) or based on diagnosis/symptoms. ${ }^{5}$

Intracerebral hemorrhagic are considered to have a higher mortality than ischemic stroke. ${ }^{1}$ The risk factors are divided into non-modifiable and modifiable risk factors. Some of modifiable risk factors are hypertension, obesity, smoking, diabetes mellitus, hyperuricemia, and heavy alcohol consumption, while the non-modifiable risk factors are age, race, sex, and genetics. ${ }^{6,7}$

Due to the lack of intracerebral hemorrhage stroke data in Indonesia, especially in West Java

Correspondence: Sabrina Putri Lofissa, Faculty of Medicine, Universitas Padjadjaran, Jalan Raya Bandung-Sumedang Km.21, Jatinangor, Sumedang, Indonesia, Email: putrilofissa@gmail.com 
Table 1 Demographic Characteristic based on Gender in 2007-2016

\begin{tabular}{|c|c|c|c|c|c|c|c|c|c|c|}
\hline \multirow{2}{*}{ Gender } & \multicolumn{2}{|c|}{ 2007-2008 } & \multicolumn{2}{|c|}{ 2009-2010 } & \multicolumn{2}{|c|}{ 2011-2012 } & \multicolumn{2}{|c|}{ 2013-2014 } & \multicolumn{2}{|c|}{ 2015-2016 } \\
\hline & $\mathbf{n}$ & $\%$ & $\mathbf{n}$ & $\%$ & $\mathbf{n}$ & $\%$ & $\mathbf{n}$ & $\%$ & n & $\%$ \\
\hline Male & 119 & 47.0 & 103 & 36.3 & 99 & 42.7 & 97 & 48.0 & 96 & 48.7 \\
\hline Female & 134 & 53.0 & 181 & 63.7 & 133 & 57.3 & 105 & 52.0 & 101 & 51.3 \\
\hline Total & 253 & 100 & 284 & 100 & 232 & 100 & 202 & 100 & 197 & 100 \\
\hline
\end{tabular}

Province which was known to have the most stroke patients in Indonesia, this study was carried out to identify the demography and risk factors among intracerebral hemorrhagic patients at Dr. Hasan Sadikin General Hospital as a referral hospital in West Java.

\section{Methods}

The method used in this study was a descriptive cross sectional design which was carried out at the Department of Neurology, Dr. Hasan Sadikin General Hospital from August 2016 to May 2017. The ethics approval has been obtained from Dr. Hasan Sadikin General Hospital and the Faculty of Medicine, Universitas Padjadjaran Health Research Ethics Committee before starting to collect data. The data involved were medical resumes from January 2007 to December 2016 by total sampling with 2259 sample size. The inclusion criteria subjects were intracerebral hemorrhage stroke patients diagnosed in the first admission approved by a computed tomography (CT) scan and hospitalized from 2007 to2016 at Dr. Hasan Sadikin General Hospital. Incomplete data or missing data of intracerebral hemorrhagic patients' medical resume were excluded in this study.

The variables of demography characteristics included in this study were age, gender, educational level, and occupation. The other variables based on risk factors were hypertension, dyslipidemia, hyperuricemia, diabetes mellitus, and kidney disease. Furthermore, data was processed by Microsoft Office Excel 2010 and presented in tables.

\section{Results}

Among 2259 intracerebral hemorrhagic patients at Dr. Hasan Sadikin General Hospital in the period of 2007-2016; only 1168 patients met the inclusion criteria (aged 14-86 years). The total inclusion subjects consisted of 514 male (aged 15-86 years) and 654 female (aged 14-86 years) (Table 1 ).

The intracerebral hemorrhagic stroke increases with age. The highest age category was 50-59, while the lowest prevalence occurred at age $<40$ years with an increase in prevalence from $4 \%$ in $2007-2008$ to $12.2 \%$ in 2015-2016 (Table 2).

Moreover, non-occupation patients had the highest prevalence in 2007-2016. Among them were students, housewives, the unemployed and retiree, followed by blue collars and agricultural workers such as farmers, fishermen, and laborers. Meanwhile, employee and entrepreneur were the two jobs with the lowest prevalence, with an increased prevalence reaching $18.8 \%$ for employee and

Table 2 Demographic Characteristic based on Age Category in 2007-2016

\begin{tabular}{|c|c|c|c|c|c|c|c|c|c|c|}
\hline \multirow{2}{*}{$\begin{array}{c}\text { Age Category } \\
\text { (years }\end{array}$} & \multicolumn{2}{|c|}{ 2007-2008 } & \multicolumn{2}{|c|}{ 2009-2010 } & \multicolumn{2}{|c|}{ 2011-2012 } & \multicolumn{2}{|c|}{ 2013-2014 } & \multicolumn{2}{|c|}{ 2015-2016 } \\
\hline & $\mathbf{n}$ & $\%$ & $\mathbf{n}$ & $\%$ & $\mathbf{n}$ & $\%$ & $\mathbf{n}$ & $\%$ & $\mathbf{n}$ & $\%$ \\
\hline$<40$ & 10 & 4 & 11 & 3.9 & 25 & 10.8 & 14 & 7 & 24 & 12.2 \\
\hline $40-49$ & 51 & 20.2 & 57 & 20.1 & 45 & 19.3 & 37 & 18.3 & 53 & 27 \\
\hline $50-59$ & 78 & 30.8 & 112 & 39.4 & 61 & 26.3 & 73 & 36.1 & 61 & 30.9 \\
\hline $60-69$ & 73 & 28.8 & 63 & 22.2 & 60 & 25.9 & 41 & 20.3 & 41 & 20.8 \\
\hline$\geq 70$ & 41 & 16.2 & 41 & 14.4 & 41 & 17.7 & 37 & 18.3 & 18 & 9.1 \\
\hline Total & 253 & 100 & 284 & 100 & 232 & 100 & 202 & 100 & 197 & 100 \\
\hline
\end{tabular}


Table 3 Demographic Characteristic based on Occupation in 2007-2016

\begin{tabular}{|c|c|c|c|c|c|c|c|c|c|c|}
\hline \multirow{2}{*}{ Occupation } & \multicolumn{2}{|c|}{ 2007-2008 } & \multicolumn{2}{|c|}{ 2009-2010 } & \multicolumn{2}{|c|}{ 2011-2012 } & \multicolumn{2}{|c|}{$2013-2014$} & \multicolumn{2}{|c|}{$2015-2016$} \\
\hline & $\mathbf{n}$ & $\%$ & $\mathbf{n}$ & $\%$ & $\mathbf{n}$ & $\%$ & $\mathbf{n}$ & $\%$ & $\mathbf{n}$ & $\%$ \\
\hline Non-occupation & 152 & 60.1 & 186 & 65.5 & 153 & 65.9 & 117 & 57.9 & 109 & 55.3 \\
\hline \multicolumn{11}{|l|}{ Occupation } \\
\hline \multicolumn{11}{|l|}{ White collar worker } \\
\hline Employee & 39 & 15.4 & 19 & 6.7 & 10 & 4.3 & 17 & 8.4 & 37 & 18.8 \\
\hline Entrepreneur & 5 & 2.0 & 23 & 8.1 & 35 & 15.1 & 23 & 11.4 & 28 & 14.2 \\
\hline $\begin{array}{l}\text { Blue collar and } \\
\text { agricultural Worker }\end{array}$ & 57 & 22.5 & 56 & 19.7 & 34 & 14.7 & 45 & 22.3 & 23 & 11.7 \\
\hline Total & 253 & 100.0 & 284 & 100.0 & 232 & 100.0 & 202 & 100.0 & 197 & 100.0 \\
\hline
\end{tabular}

14.2\% for entrepreneur in 2015-2016 (Table $3)$.

Based on the difference of educational level; patients who graduated from elementary school or less, were the highest prevalence within 10 years with a declining prevalence in 2015-2016. Meanwhile, a decrease in prevalence was shown at the higher educational level among diploma/college/ university graduate patients (Table 4).

Moreover, based on risk factors, the subjects had one or more risk factors. Hypertension was the highest risk factor, with the decreasing prevalence from $78.8 \%$ in $2007-2008$ to $55.3 \%$ in 2015-2016, followed by dyslipidemia, diabetes mellitus, and hyperuricemia with an increased prevalence in 2015-2016. Meanwhile, there were no significant changes of kidney disease from year to year (Table 5).

\section{Discussion}

A hospital based study showed that male predominated by $51 \%$ between the ages of 21 78 and the mean age is 50 years. The female

Table 4 Demographic Characteristic based on Education Level in 2007-2016

\begin{tabular}{|c|c|c|c|c|c|c|c|c|c|c|}
\hline \multirow{2}{*}{$\begin{array}{c}\text { Education Level } \\
\text { Graduates }\end{array}$} & \multicolumn{2}{|c|}{$2007-2008$} & \multicolumn{2}{|c|}{$2009-2010$} & \multicolumn{2}{|c|}{ 2011-2012 } & \multicolumn{2}{|c|}{ 2013-2014 } & \multicolumn{2}{|c|}{ 2015-2016 } \\
\hline & $\mathbf{n}$ & $\%$ & $\mathbf{n}$ & $\%$ & $\mathbf{n}$ & $\%$ & $\mathbf{n}$ & $\%$ & $\mathbf{n}$ & $\%$ \\
\hline $\begin{array}{l}\text { Elementary school/ } \\
\text { less }\end{array}$ & 187 & 74 & 219 & 77.1 & 131 & 56.5 & 132 & 65.4 & 102 & 51.8 \\
\hline JHS & 32 & 12.6 & 34 & 12 & 68 & 29.3 & 35 & 17.3 & 33 & 16.7 \\
\hline SHS & 33 & 13.0 & 29 & 10.2 & 31 & 13.3 & 33 & 16.3 & 51 & 25.9 \\
\hline $\mathrm{D} / \mathrm{C} / \mathrm{U}$ graduates & 1 & 0.4 & 2 & 0.7 & 2 & 0.9 & 2 & 1 & 11 & 5.6 \\
\hline Total & 253 & 100 & 284 & 100 & 232 & 100 & 202 & 100 & 197 & 100 \\
\hline
\end{tabular}

Note: JHS: Junior High School, SHS: Senior High School, D: Diploma, C: College, U: University

Table 5 Modifiable Risk Factors in 2007-2016

\begin{tabular}{|c|c|c|c|c|c|c|c|c|c|c|}
\hline \multirow{2}{*}{$\begin{array}{l}\text { Modifiable Risk } \\
\text { Factor }\end{array}$} & \multicolumn{2}{|c|}{ 2007-2008 } & \multicolumn{2}{|c|}{ 2009-2010 } & \multicolumn{2}{|c|}{ 2011-2012 } & \multicolumn{2}{|c|}{$2013-2014$} & \multicolumn{2}{|c|}{$2015-2016$} \\
\hline & $\mathbf{n}$ & $\%$ & $\mathbf{n}$ & $\%$ & $\mathbf{n}$ & $\%$ & $\mathbf{n}$ & $\%$ & $\mathbf{n}$ & $\%$ \\
\hline Hypertension & 252 & 78.8 & 283 & 65.1 & 228 & 71.7 & 200 & 62.7 & 193 & 55.3 \\
\hline Dislipidemia & 26 & 8.1 & 95 & 21.8 & 47 & 14.8 & 68 & 21.3 & 83 & 23.8 \\
\hline Hyperuricemia & 8 & 2.5 & 30 & 6.9 & 23 & 7.2 & 34 & 10.7 & 39 & 11.2 \\
\hline Diabetes Mellitus & 21 & 6.6 & 25 & 5.7 & 20 & 6.3 & 14 & 4.4 & 31 & 8.9 \\
\hline Kidney Disease & 13 & 4.1 & 2 & 0.5 & 0 & 0.0 & 3 & 0.9 & 3 & 0.9 \\
\hline Total & 320 & 100.0 & 435 & 100.0 & 318 & 100.0 & 319 & 100.0 & 349 & 100.0 \\
\hline
\end{tabular}


is rather older with age ranging from 24-83 years with the mean age of 53 years. ${ }^{6}$ However, the results of this study showed female were greater in number than male within 10 years. Women in pregnancy or postpartum, the longer life expectancy, older age or over 75 years can be considered as the high prevalence found in female. ${ }^{7,8}$ In this study, the prevalence patient' age of $>70$ years were greater in female with $51.1 \%$ in the recent two years (2015-2016).

Stroke incidence increases with age and is expected to double in every decade between the ages of 45 to 85 years. It is most likely to occur between the ages of 55-64 years, while in the age below 40 years is still uncommon. ${ }^{6}$ The results of this study identified the highest prevalence was found in the age group 55-59 years and an increase of prevalence among age $<40$ in the last ten years. The increased prevalence among young adults (less than 40 ) in the recent years is associated with the increasing consumption of junk food and soda or sweet beverages which exceeds the recommended calories per day in young adults. Another factor is the prolong inactivity or less frequent physical activity increases the risk of cardiovascular disease. ${ }^{9}$

Based on a study conducted by the Korean Community Health Survey ${ }^{10}$ (KCHS) in $2010,78.8 \%$ of the stroke patients are with no occupation. This study revealed those with no occupation within 10 years have the highest prevalence, followed by those who work as blue collar and agricultural workers, and least likely to occur among white collar workers who work as employees or entrepreneurs. The white collar workers tend to get adequate protection, supportive environmental conditions with lower physical demands, and were financially better, while those with no occupation and blue collar and agricultural workers are classified as a low socioeconomic group that have limited access to health facilities and tend to have minimal education. Other low socioeconomic groups such as laborers or other blue collar and agricultural workers are frequently affected by physical, chemical, and psychosocial exposure included noise and heat pollution and other environmental factors, thus increase the cardiovascular risk. ${ }^{10,11}$ However, in this study the low socioeconomic factor is still insufficient to conclude those with no occupation, and blue collar and agricultural workers have a high risk of stroke. The subjects with no occupations in this study were students, housewives, the unemployed and retired. This study showed that the prevalence of age above 50 years was greater than the age below 50, therefore the majority of the subjects might be considered as retired with old age.

Based on the educational level, the result of this study showed that patients graduated from elementary school or less had the highest prevalence within 10 years and were $51.8 \%$ in the last two years, while those graduated from diploma/college/university had the lowest prevalence within 10 years, and were approximately $5.6 \%$ in the last two years. In agreement in this study, previous studies reported that educational attainment represents a form of health awareness and socioeconomic status. People with higher education also tend to have an urgency to understand the health consequences, while people with lower educational level are associated with cognitive impairment and unhealthy lifestyles. ${ }^{11,12}$

Based on the Interstroke study involving 22 countries reported that hypertension is the highest prevalence among intracerebral hemorrhagic patients with 83\% (551/663), and stronger for intracerebral hemorrhagic than ischemic stroke. ${ }^{13}$ Chronic hypertension leads to vascular changes include fibroid necrosis (lipohyalinosis) of penetrating arteries and arterioles supplying the white matters, microaneurysm formation, luminal narrowing and microhemorrhage, all of which are susceptible to rupture. ${ }^{14,15}$

In this study, hypertension was the highest prevalence among intracerebral hemorrhagic patients and there was a decreasing hypertension prevalence from year to year. An increased awareness of people who have checked into health facilities could be a factor of decreasing hypertension prevalence. ${ }^{3}$

A study conducted by the Chongqin Center for Disease Control and Prevention in 2014 showed $37.4 \%$ dyslipidemia among stroke patients had hypertriglyceridemia and low High-density lipoprotein (HDL) cholesterol. This phenomenon is likely due to the high carbohydrates intake and high-fat-diets in recent decades, which affects the high serum triglyceride level. ${ }^{16}$ The result in this study is in agreement with the previous study that people with dyslipidemia were found in intracerebral hemorrhagic patients and $23.8 \%$ were in the last two years.

Hyperuricemia was associated with cardiovascular disease and other risk factors such as hypertension, high triglyceride and cholesterol serum, and metabolic syndrome, though, the mechanism is poorly understood. However, the role of uric acid is 
controversial since on the other hand uric acid has neuroprotective effects by acting as a free radical scavenger ${ }^{17}$ In this study, the prevalence of hyperuricemia among intracerebral hemorrhagic patients increased from year to year, reaching $11.2 \%$ in recent two years.

Furthermore, Interstroke study showed the prevalence of diabetes mellitus among intracerebral hemorrhagic patients were $10 \%{ }^{13}$ There is not much difference between the previous studies and ours since the recent prevalence in two years in this study were $8.6 \%$. Diabetes mellitus is one of the cardiovascular risk that accelerates the atherosclerosis progression and damages microvasculature which leads to hypertension. ${ }^{2,6}$

In this study, kidney disease was the least likely to occur among intracerebral hemorrhagic patients and had no significant changes from year to year. Atherosclerosis Risk in Communities (ARIC) reported that a low creatinine clearance among Chronic Kidney Disease (CKD) and anemia were associated with the increase risk for stroke. A study in $\operatorname{Japan}^{18}$ revealed that CKD with macroalbuminuria are independent risk factors for stroke. However, a single kidney disease is still insufficient as an independent risk factor for stroke. ${ }^{18}$

In conclusion, the high prevalence among intracerebral hemorrhage stroke is frequently found in female, older age, nonoccupation and low level of education person. Hypertension is the highest risk factor, followed by dyslipidemia, diabetes mellitus, and hyperuricemia with deleterious effect on microvasculature. Metabolic syndrome includes high cholesterol and plasma glucose level, high blood pressure, and hyperuricemia is associated with cardiovascular disease and diabetes mellitus type 2 which reflects the stroke patients. A bad lifestyle includes high intake calories from junk food, smoking and less physical activity are enough to explain the reason of increasing prevalence of diabetes mellitus, dyslipidemia, and hyperuricemia in the recent years in this study. ${ }^{17,19}$

This study had certain limitations. The cross-sectional design of this study was limited in analyzing the correlation between variables of intracerebral hemorrhagic stroke. Additionally, the retrospective study using medical resumes was also a limitation in this study since there were many missing data and unspecific information about the variables of this study. The missing data of medical resume might be due to the ten-year-period of this study. Based on the Policy of the Indonesian Health Minister in 2008 which stated that medical records of more than 5 years would be destroyed, except the return summaries and medical action approvals. ${ }^{20}$

The suggestion for a further study is a prospective study in order to follow up the progression of risk factors in association to intracerebral hemorrhage stroke. Furthermore, this study can be improved by conducting a research using complete or primary medical records. In addition, these results highlight the extensive need for medical checkups, routine screening programs, and appropriate intervention programs in health care instances aimed at lifestyle changes to reduce the intracerebral hemorrhage stroke risk factors.

\section{References}

1. Andersen KK, Olsen TS, Dehlendorff C, Kammersgaard LP. Hemorrhagic and ischemic strokes compared: Stroke severity, mortality, and risk factors. Stroke. 2009;40(6):2068-72.

2. Herzig R, Vlachová I, Mareš J, Gabryš M, Šaňák D, Školoudík D, et al. Occurrence of diabetes mellitus in spontaneous intracerebral hemorrhage. Acta Diabetol. 2007;44(4):201-7.

3. Badan Penelitian dan Pengembangan. Riset Kesehatan Dasar 2013. Jakarta: Litbangkes; 2013.

4. World Health Organization. WHO Statistical Profile. Geneva:WHO; 2015.

5. Kementerian Badan Litbangkes. Pusat Data dan Informasi Kementrian Kesehatan RI. Jakarta: Badan Litbangkes; 2014.

6. Jahirul MS, Choudhury H, Chowdhury TI, Nayeem A. Modifiable and Non-Modifiable Risk Factors of Stroke: A Review Update. J Natl Inst Neurosci Bangladesh. 2015;1(1):22-6.

7. Grysiewicz RA, Thomas K, Pandey DK. Epidemiology of Ischemic and Hemorrhagic Stroke: Incidence, Prevalence, Mortality, and Risk Factors. Neurol Clin NA. 2008;26(4):871-95.

8. Reeves MJ, Bushnell CD, Howard G, Gargano JW, Duncan PW, Lynch G, et al. Sex differences in stroke: epidemiology, clinical presentation, medical care, and outcomes. Lancet Neurol. 2008;7(10):6574.

9. Sorgi BA, Dean SC, Meekins K, Chen P, Ph D, Halpern CT, et al. Lifestyle and Behavior in Young Adulthood: The National Longitudinal Study of Adolescent to Adult 
Health. Add Healtth. 2015;2(2):1-8.

10. Hyun-ju J, Kim-ki J, Chun-in A, Ok-kon M. The relationship between stroke patients ' socio-economic conditions and their quality of life: the 2010 Korean community health survey. J Phys Ther Sci 2015;27(3):2-5.

11. Clougherty JE, Souza K, Cullen MR. Work and its role in shaping the social gradient in health. Ann N Y Acad Sci. 2010;1186(1):102-24.

12. Honjo $K$, Iso $H$, Ikeda $A$, Inoue $M$, Tsugane S. Education level and physical functional limitations among Japanese community residents-gender difference in prognosis from stroke. BMC public health. 2009;9(1):1-8.

13. Donnell MJO, Xavier D, Liu L, Zhang H, Chin SL, Rao-melacini P, et al. Risk factors for ischaemic and intracerebral haemorrhagic stroke in 22 countries (the INTERSTROKE study): a case-control study. Lancet. 2010;376(9735):116-23

14. Davisson RL. Hypertension and Cerebrovascular Dysfunction. Cell metab.
2009;7(6):476-84.

15. Caceres JA, Goldstein JN. Intracranial Hemorrhage. Emerg Med Clin North Am. 2013;30(3):771-94.

16. Qi L, Ding X, Tang W, Li Q, Mao D, Wang Y. Prevalence and Risk Factors Associated with Dyslipidemia in. Int J Environ Res Public Health. 2015;12(10):13455-65.

17. Mehrpour M, Khuzan M, Najimi N, Motamed MR. Serum uric acid level in acute stroke patients. MJIRI. 2012;26(2):66-72.

18. Khella S, Bleicher MB. Stroke and its prevention in chronic kidney disease. Clin J Am Soc Nephrol. 2007;2(6):1343-51.

19. Takahashi T, Harada M, Kikuno T, Ujihara M, Sadamitsu D, Manabe Y, et al. Prevalence of metabolic syndrome in stroke patients: a prospective multicenter study in Japan. Acute Med Surg. 2014;1(1):17-22.

20. Menteri Kesehatan Republik Indonesia. Peraturan Menteri Kesehatan Republik Indonesia Nomor 269/Menkes/Per/ III/2008. Jakarta: Kementrian Kesehatan Republik Indonesia; 2008. 